\title{
Offset Strip Fin nanocomposite polymer heat exchanger development
}

\author{
B. Fassolette, P. Bonnamy \& J. A. Gruss \\ Laboratoire d'études thermiques, CEA DRT/LITEN/LETH, \\ Grenoble, France
}

\begin{abstract}
This paper describes an analytical and numerical design method for compact heat exchangers using nanocomposite polymer fins. The heat exchanger considered is a plate and fin air/water type. There are OSF fins with longitudinal gaps on the air side and minichannels on the water side. The analytical model is based on several state of the art correlations like the Manglik and Bergles correlation for OSF fins, introducing some corrections due to the gap along the fin. A global analytical design method allowing optimization of the heat exchanger is described. A CFD model of the fins has been developed in order to introduce corrections due to the specific geometry of the polymer fins. Prototypes developed with industrial partners will be tested in our lab to validate this model. Keywords: heat exchange, polymer, nanocomposite, simulation.
\end{abstract}

\section{Introduction}

For several years, special attention has been focused on alternative materials that can replace metals ( $\mathrm{Al}$, stainless steel, $\mathrm{Cu}, \mathrm{Ti}$ ) for the manufacture of heat exchangers (HX). Indeed, metals have become more and more expensive and require a great deal of energy for processing. Polymers have some advantages for use in HX as chemical resistance, antifouling properties, manufacturing cost... but their main drawbacks are their poor thermal conductivity, lower mechanical resistance and limited temperature range. Adding nanofillers may improve the properties of polymers and permit to design efficient and cost effective HX for low to moderate temperature applications.

An HX has been designed using this new material for a marine Intercooler heat exchanger dedicated to cool compressed air with seawater. This HX may 
replace the traditional copper-tube/aluminum-fins design. We describe here the design of a plate and fin HX using Offset Strip Fins on the air side. Specific models have been developed for these fins that will be validated by prototype experiments.

This work has been financed by the EEC FP7 THERMONANO project involving several laboratories : Politecnico di Torino (Italy) - coordinator , TU Berg-akademie Freiberg (Germany), Polymer Institute (Slovakia), Commissariat à l'Énergie Atomique et aux Energies Alternatives (France) and industrial companies : Onni-Stamp S.r.l.(Italy), Nanocyl SA, Astra Refrigeranti SpA (Italy), Simona AG (Germany), SGL Carbon GmbH (Germany).

\section{Bibliography}

Polymer HX have already been used in many niche applications for several decades. Reviews on polymer HX are available in the literature (see Deronzier et al. [1], Zaheed et al. [2], T'Joen et al. [3]). Several types of heat exchangers are available in the market: shell and tube, plates, coils..., using various polymers: PVDF, PP, Teflon, Polyamide, PPS, PPO or PEEK. Some techno polymers like PPS, LCP or PEEK can withstand continuously a temperature higher than $200^{\circ} \mathrm{C}$. Several companies like AB Segerfröjd [4], Ametek [5], Georg Fisher [6], Greenbox [7], Milieupartners [8] and SGL Carbon [9] have products on the market. The thermal conductivity of polymers is much lower than that of metals, generally between 0.1 and $0.4 \mathrm{~W} / \mathrm{mK}$. Adding fillers and carbon nanotubes (CNT) can improve mechanical and thermal properties reaching more than 2 $\mathrm{W} / \mathrm{m} . \mathrm{K}$ with a relatively low CNT content (Han and Fina [10]).

Offset Strip Fins (OSF) have been used for years in plate and fin HX, however thermally conductive metal fins are usually being used and most available design correlations have been developed for metal OSF fins.

Developing polymer OSF fins have some differences with metal OSF fins: The OSF correlations have been developed using experimental data coming from aluminum surfaces and may not be valid with polymer fins that may have different geometrical parameters: large thickness, round edges, longitudinal gap. Then, the poor thermal conductivity of polymers requires the computation of a fin efficiency

Subramanian [11] has studied the design OSF fins made with longitudinal gap and round edges in the development of a ceramic high temperature heat exchanger made with $\mathrm{SiC}$.

Kim et al. [12] have studied numerically OSF fins; he has developed a specific correlation that may be used for OSF with large blockage ratio.

Dong et al. [13], using numerical and experimental studies have developed a correlation that can be used for OSF fins with entrance effects.

Michel [14] has studied experimentally and numerically OSF fins and had made parametric studies and tried to optimize fin length, thickness and longitudinal gap between fins mainly by 2D simulation.

Tochon [15] studied metallic OSF and showed that it is relevant to have a gap between consecutive rows of fins, since pressure losses are reduced by around $25 \%$ while heat transfer is reduced by around $5 \%$ only. 


\section{Design of the heat exchanger}

The HX is an air/water cross-flow plate and fin heat exchanger. Specifications are given in Table 1.

A general view of the heat exchanger core is given in Figure 1.

Table 1: Heat exchanger specifications.

\begin{tabular}{|c|c|}
\hline AIR SIDE & \\
\hline Mass flow rate $[\mathrm{Kg} / \mathrm{s}]$ & 0.198 \\
\hline Inlet pressure $[\mathrm{bar} \mathrm{abs}]$ & 3 \\
\hline Inlet temperature $\left[{ }^{\circ} \mathrm{C}\right]$ & 135 \\
\hline Outlet temperature $\left[{ }^{\circ} \mathrm{C}\right]$ & 55.7 \\
\hline Mean temperature $\left[{ }^{\circ} \mathrm{C}\right]$ & 95.4 \\
\hline Max pressure drop $[\mathrm{mbar})$ & 1.6 \\
\hline WATER SIDE & \\
\hline Mass flow rate $[\mathrm{Kg} / \mathrm{s}]$ & 1.370 \\
\hline Inlet pressure $[\mathrm{bar}$ abs] & 4 \\
\hline Inlet temperature $\left[{ }^{\circ} \mathrm{C}\right]$ & 51.5 \\
\hline Outlet temperature $\left[{ }^{\circ} \mathrm{C}\right]$ & 54.3 \\
\hline Mean temperature $\left[{ }^{\circ} \mathrm{C}\right]$ & 52.9 \\
\hline Inlet pressure $[\mathrm{bar}]$ & 4 \\
\hline Max pressure drop $[\mathrm{mbar}]$ & 100 \\
\hline GENERAL PERFORMANCE & \\
\hline Heat rate $[\mathrm{W}]$ & 15910 \\
\hline Efficiency $[-]$ & 0.95 \\
\hline
\end{tabular}

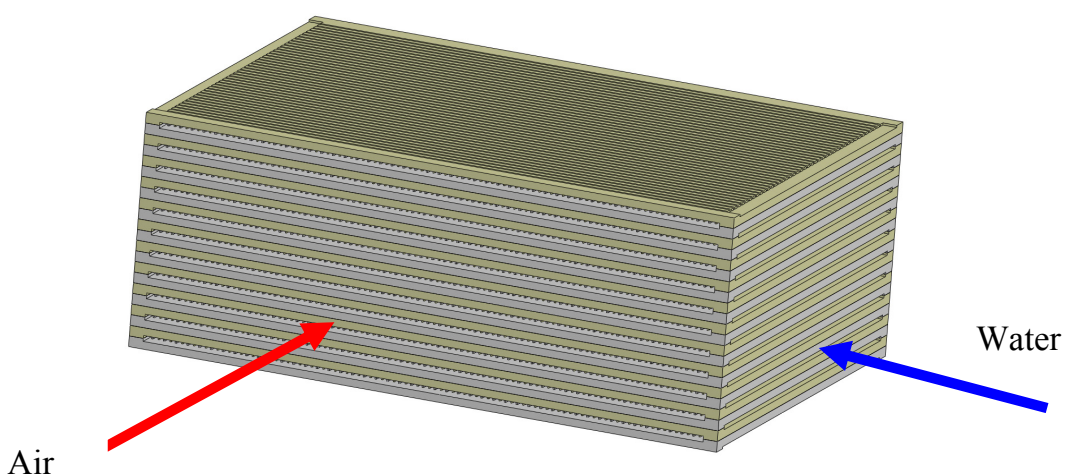

Figure 1: General view of the HX.

Two processes are being used for manufacturing the plates: injection and compression molding.

For the injection process, a PA6/CNT nanocomposite has been developed with a thermal conductivity reaching $2 \mathrm{~W} / \mathrm{m} . \mathrm{K}$ 
For the compression molding process, a PVDF/Graphite/CNT nanocomposite has been developed with a thermal conductivity reaching $12 \mathrm{~W} / \mathrm{m} . \mathrm{K}$.

On air side, the fin thickness being small (around $0.5 \mathrm{~mm}$ for injection, and around $1 \mathrm{~mm}$ for compression molding), the fins are interlaced for better mechanical resistance. On the water side, the fins are thicker and in contact tip to tip. Two consecutive rows are separated with a gap as recommended by Tochon [15]. Details of the fin structure for both processes are given in and Figures 2 and 3.

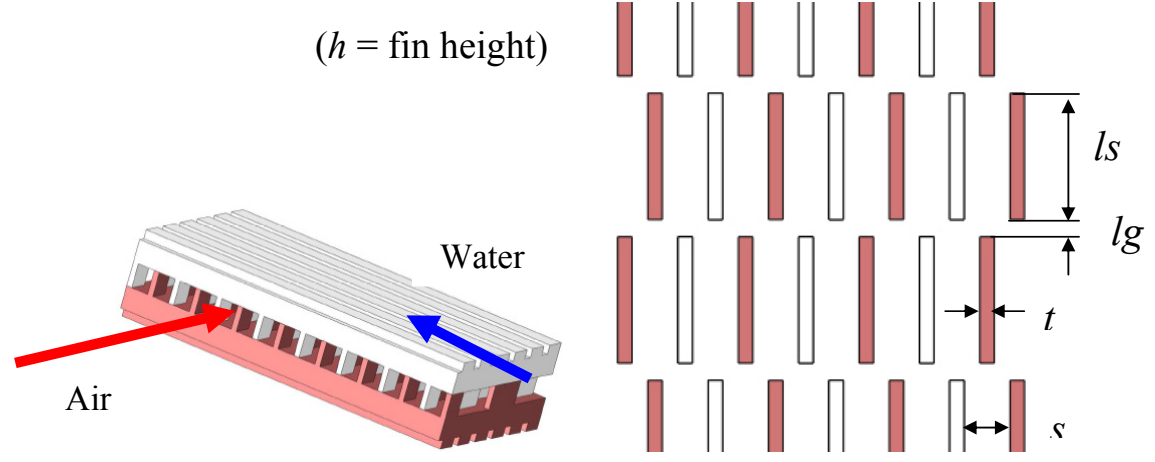

Figure 2: $\quad$ Detailed view of injected plates.

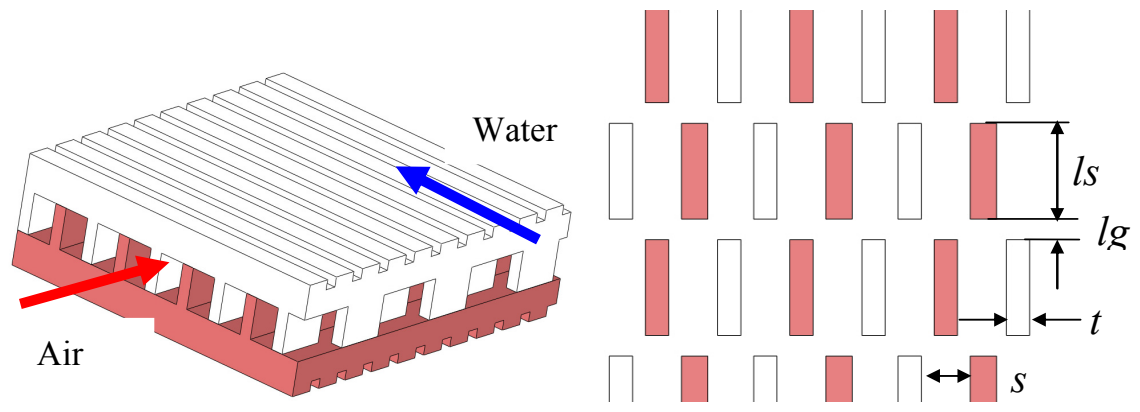

Figure 3: Detailed view of compression molding plates.

\section{Global sizing model}

\subsection{Introduction}

A global sizing model was developed and implemented using Microsoft Excel in order to optimize the HX geometry (number of plates, geometry of the fins...), while respecting the specifications of the project (Table 1). It is an iterative procedure that begins computing a global heat transfer factor $U_{g}$ and a $N T U$ from the specifications of the $\mathrm{HX}$ and from initialized values of geometrical parameters. A primary area $A$ is deduced with (1). Then, geometrical parameters can be optimized from this primary area, and used as new geometrical 
parameters for the next iteration. This procedure is represented in Figure 4. $U_{g}$ is obtained from the convective heat transfer factor and the fin efficiency. In the following sections are detailed the ways to get these factors, along with the NTU.

$$
A=\frac{N T U \cdot C_{\min }}{U_{g}}
$$

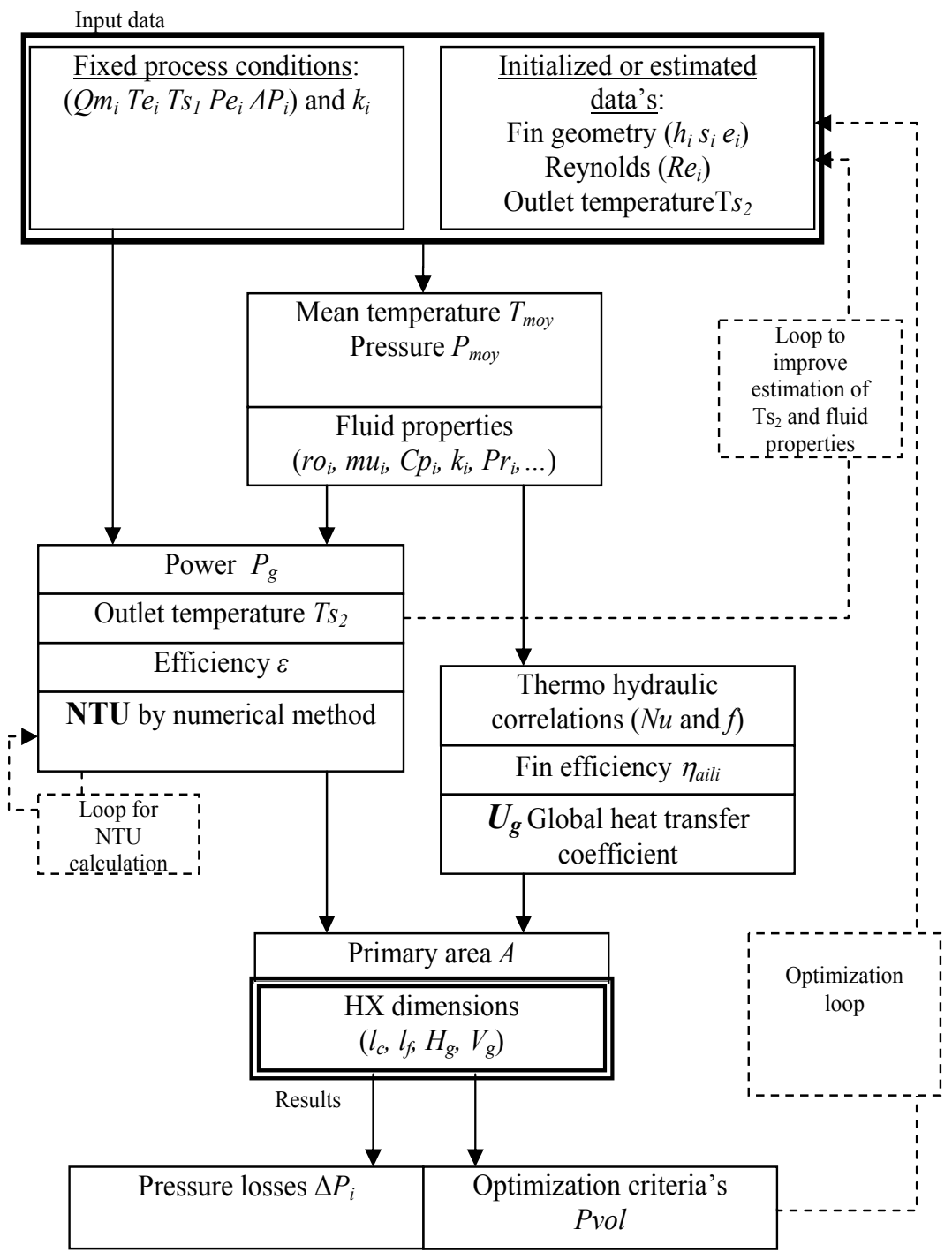

Figure 4: Global sizing model. 


\subsection{Correlations for rectangular ducts}

For $\mathrm{Re}>3000$ on the water side of the HX, friction factor and Nusselt number through straight fins can be obtained using the Gnielinski (2) and Blasius (3) correlations. They are appropriate for turbulent flows through rectangular ducts.

$$
\begin{gathered}
N u=\frac{(\operatorname{Re}-1000) \operatorname{Pr} f / 2}{1+12.7(f / 2)^{1 / 2}\left(\operatorname{Pr}^{2 / 3}-1\right)} \\
f=0.079 \operatorname{Re}^{-1 / 4}
\end{gathered}
$$

For laminar flows $(\operatorname{Re}<2300)$, correlations of Marco and Han (4) and Shah and London (5) can be used:

$$
\begin{gathered}
N u=7.541\left(1-2.61 \operatorname{Rap}+4.97 \operatorname{Rap}^{2}-5.119 \operatorname{Rap}^{3}+2.702 \operatorname{Rap}^{4}-0.548 \operatorname{Rap}^{5}\right) \\
f=\frac{24}{\operatorname{Re}}\left[\left(1-(1.3553 \operatorname{Rap})+\left(1.9467 \operatorname{Rap}^{2}\right)-\left(1.7012 \operatorname{Rap}^{3}\right)+\left(0.9564 \operatorname{Rap}^{4}\right)-\left(0.2537 \operatorname{Rap}^{5}\right)\right]\right. \\
\operatorname{rap}_{i}=\frac{\operatorname{MIN}\left(h_{i}, s_{i}\right)}{\operatorname{MAX}\left(h_{i}, s_{i}\right)}
\end{gathered}
$$

These correlations of laminar and turbulent flows are fitted using a third degree polynomial, in order to evaluate the factors of transitional flows.

\subsection{Correlations for OSF}

Based on an appropriate definition of the hydraulic diameter (7), Manglik and Bergles [16] developed the correlations (8) and (9) for standard thin metallic Offset Strip Fins. In their range of validity, given by (10), these correlations fit a large amount of experimental data with an accuracy of $+/-20 \%$, no matter the flow: laminar, transitional or turbulent state. A problem in using the correlations of Manglik and Bergles [16] is the fact that fins geometrical parameters and Reynolds numbers of our flows are outside the validity range of these correlations, and they were developed for OSF without any gap.

However they were implemented in the global sizing model. Then, to take account of the gaps, the standard formulae (7), (8), (9) and (10) were calculated using $l_{s}+l_{g}$ instead of the sole fin length $l_{s}$, and the calculated $f$ and $j$ factors were reduced by $25 \%$ and $5 \%$ respectively as recommended by Tochon [15].

$$
\begin{gathered}
D h=\frac{4 A c^{*} l s}{A}=\frac{s^{*} h^{*} l s}{2\left(s * l s+h^{*} l s+e^{*} h\right)+e^{*} s} \\
j=0,6522 \operatorname{Re}^{-0,5403} \alpha^{-0,1541} \delta^{0,1499} \gamma^{-0,0678}\left(1+5,269 e^{-5} \operatorname{Re}^{1,340} \alpha^{0,504} \delta^{0,456} \gamma^{-1,055}\right)^{0,1}
\end{gathered}
$$




$$
\begin{gathered}
f=9,6243 \operatorname{Re}^{-0,7422} \alpha^{-0,1856} \delta^{0,3053} \gamma^{-0,2659}\left(1+7,669 e^{-8} \operatorname{Re}^{4,429} \alpha^{-0,920} \delta^{3,767} \gamma^{-0,236}\right)^{0,1} \\
0,135<\alpha=\frac{s}{h}<0,9970,012<\delta=\frac{e}{l_{s}}<0,048 \quad 0,051<\gamma=\frac{e}{s}<0,121
\end{gathered}
$$

\subsection{Fin efficiency and $U_{g}$}

The efficiency $\eta$ tot $_{i}$ of the total exchange surface is defined by (11):

$$
\eta \text { tot }_{i}=\text { beta }_{i} \text { qail }_{i}+1-\text { beta }_{i}
$$

With the following definitions of surfaces ratio beta, and the fin's surface efficiency $\eta_{a i l}$ :

$$
\begin{gathered}
\text { beta }_{i}=\frac{\text { Aail }_{i}}{\text { Atot }_{i}}=\frac{h_{i}}{h_{i}+s_{i}} \\
\text { qail }_{i}=\frac{\tanh \left(M_{i} L_{i}\right)}{M_{i} L_{i}} \\
M_{i}=\sqrt{\frac{2 \alpha_{i}}{e_{i} k_{i}}} \quad L_{i}=\frac{h_{i}}{2}
\end{gathered}
$$

Then, the global heat transfer factor is:

$$
\frac{1}{U_{g} A}=\frac{1}{\eta_{a} \alpha_{a} A_{a}}+\frac{1}{\eta_{e} \alpha_{e} A_{e}}+\frac{E p}{k A}
$$

\subsection{NTU}

NTU is obtained from solving the non-linear equation for non-mixed cross-flow heat exchanger (17), with the HX efficiency $\varepsilon$ calculated with (16).

$$
\begin{aligned}
& C^{*}=\frac{C_{\min }}{C_{\max }}=\frac{\dot{m}_{a} C p_{a}}{\dot{m}_{e} C p_{e}} \quad \varepsilon=\frac{P}{C_{\min }\left|T_{e a}-T_{e e}\right|} \\
& \varepsilon=1-E X P\left[\frac{N U T^{0,22}}{C^{*}}\left(E X P\left(-C^{*} * N U T^{0,78}\right)-1\right)\right]
\end{aligned}
$$

\subsection{Conclusions}

Using the design model above and manufacturing limits from the processes used, we designed two prototypes with optimized geometrical parameters.

Geometries of these prototypes are given in Figure 5. 


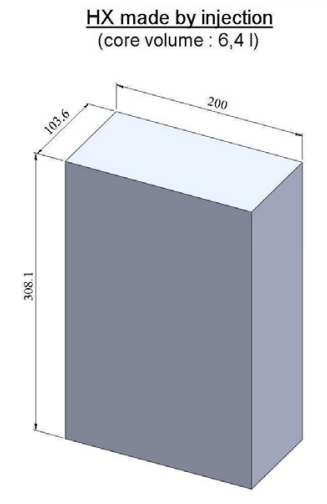

Figure 5: $\quad$ Sketches of the HX cores.

\section{CFD study: fins shape and performances}

FLUENT software was used in order to evaluate the fins performances and the best shape for their edges (rectangular or rounded) in term of classic $j / f^{1 / 3}$ factor. A prior study was performed on an OSF reference case in order to evaluate the difference between validated correlations and numerical results.

\subsection{Reference case}

Three flows through thin metallic OSF have been simulated in order to cover the interesting range of $R e$ numbers involved in THERMONANO ( $R e$ is based on $D h$ given by (8)). The chosen geometrical parameters are $h=7.8 \mathrm{~mm} ; s=1.8 \mathrm{~mm}$; $t=0.2 \mathrm{~mm}$ and $l s=5 \mathrm{~mm}$. Based on pseudo-symmetrical considerations, simulated geometry for six rows is shown in Figure 6.

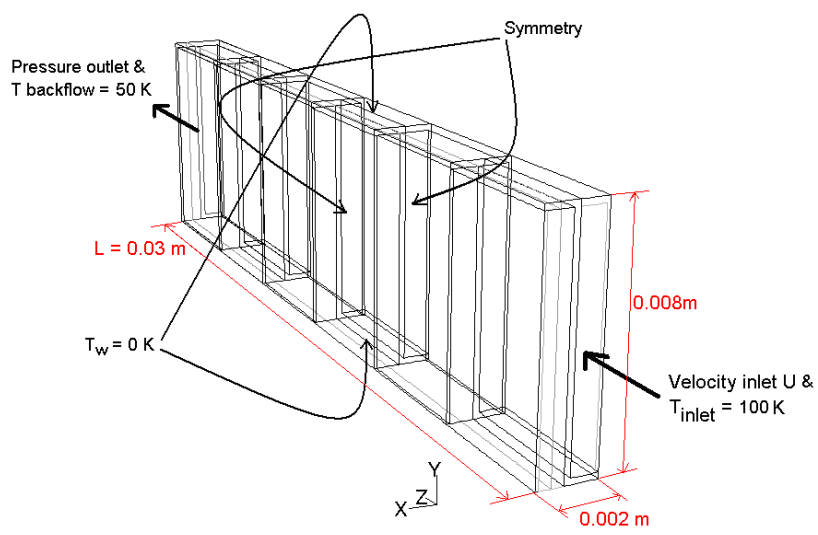

Figure 6: Geometry for the reference case. 
One mesh was created for each flow in order to have a convenient value of the non-dimensional wall distance $y^{+}$. These three flows, meshes and $y^{+}$values are:

1. $\operatorname{Re}=681,479520$ cells, $y^{+} \approx 4$,

2. $\operatorname{Re}=1108,997920$ cells, $y^{+} \approx 4$,

3. $\operatorname{Re}=1510,2476800$ cells, $y^{+} \approx 5$.

Based on FLUENT users guide recommendations, two RANS models were tested along with the laminar solver: $k$ - $\varepsilon$-RNG-Enhanced wall treatment and $k-\omega$ SST-Low Reynolds correction. Some simulations showed the validity of the meshes, the suitability of a convergence criterion set at $10^{-6}$, the periodicity of the flows on the fourth and fifth rows and then the superiority of the following settings in fitting the correlations of Manglik and Bergles:

- Pressure-velocity coupling scheme : SIMPLEC,

- Spatial discretization of gradients : Least squares cell based,

- Spatial discretization of pressure: PRESTO!,

- Spatial discretization of momentum, energy, $k, \varepsilon, \omega$ : QUICK,

Results are shown in Figures 7 and 8. The best turbulent solver is the steady $k$ $\omega$-SST-LRC. It is able to give good results in laminar as in turbulent flows, and it is the most used in literature. Such numerical simulations fit the correlations of Manglik and Bergles with an accuracy of $+/-20 \%$, and no matter the laminar, transitional or turbulent state of the flow.

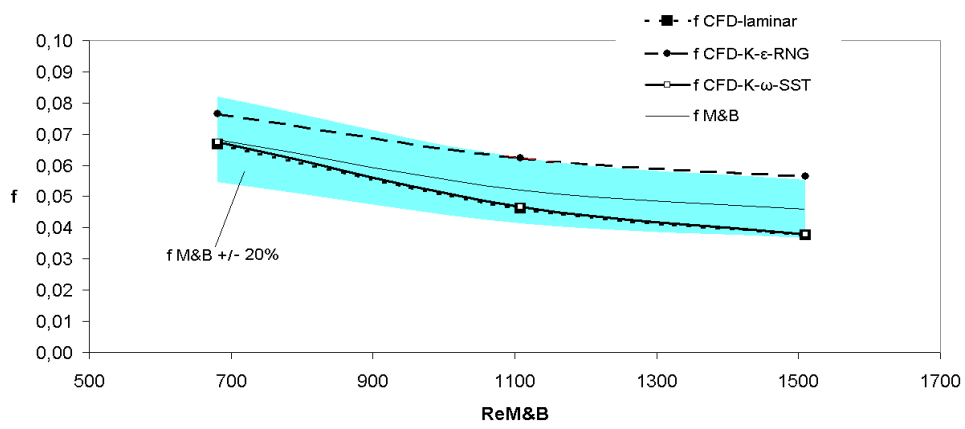

Figure 7: Numerical and correlated fanning factors on the fifth row.

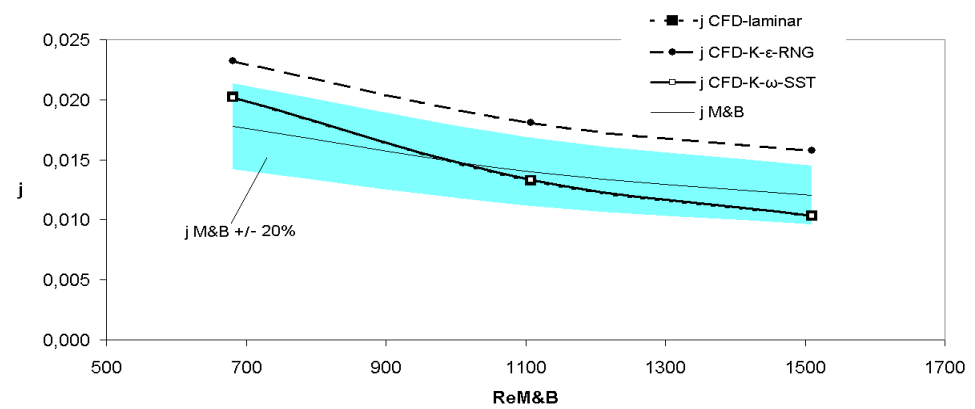

Figure 8: $\quad$ Numerical and correlated Colburn factors on the fifth row. 


\subsection{THERMONANO simulations (rectangular/rounded) results}

Four cases were simulated for the THERMONANO purpose, corresponding to two designs: injection or compression molding, and two edge shapes: sharp rectangular fin edges or rounded edges.

In the simulated geometry there is a half-height channel for the air flow, bounded by conditions of symmetry on the right, left and upper faces. The lower part of the channel is composed by a polymer nanocomposite plate, with a fixed temperature on the lower surface. Six rows of half height and half thickness fins are represented, as shown in Figure 9. This figure also shows the different fin cross sections yielded by the edges shapes.

The $R e$ numbers, mesh sizes and $y^{+}$values are:

- Injection with rectangular edges: $R e=615,60192$ cells, $y^{+} \approx 6$,

- Injection with rounded edges: $R e=615,87552$ cells, $y^{+} \approx 6$,

- Compression with rectangular edges: $R e=1648,261072$ cells, $y^{+} \approx 6$,

- Compression with rounded edges: $\operatorname{Re}=1648,450808$ cells, $y^{+} \approx 6$.

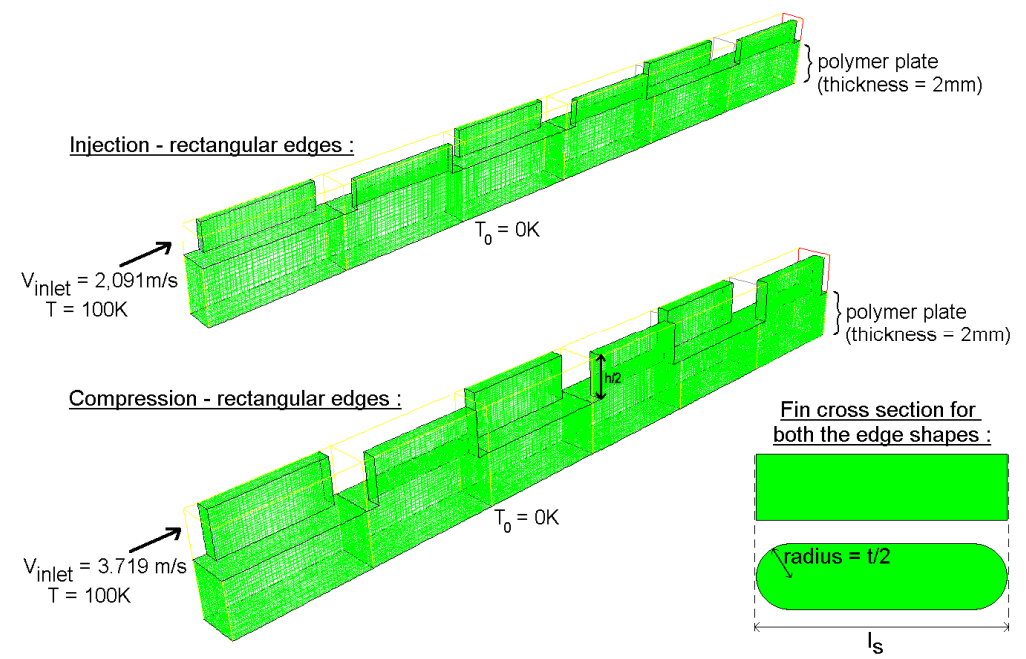

Figure 9: Simulated geometry and boundary conditions for the THERMONANO cases.

The four simulations were performed using $k-\omega$-SST-LRC model and the validated settings of the reference case. Using appropriate under-relaxation factors, the convergence criterion $10^{-6}$ can be reached. Fanning friction factors and Colburn convective heat transfer factors of the fifth row are extracted and presented in Tables 2 and 3 along with the direct results of Manglik and Bergles correlations (calculated with $l_{s}+l_{g}$ instead of $l_{s}$; without gap correction).

For both the injected and compression molded rectangular fins design, the corrected Manglik and Bergles factors ( $-25 \%$ for $f$ and $-5 \%$ for $j)$ initially taken 
Table 2: $\quad$ Results for the injection process design.

\begin{tabular}{|c|c|c|c|}
\hline & Rectangular edges & Rounded edges & Relative difference \\
\hline$f(\mathrm{CFD})$ & 0.054 & 0.043 & $-20.4 \%$ \\
\hline$f(\mathrm{M} \& \mathrm{~B})$ & 0.077 & 0.077 & - \\
\hline $\begin{array}{c}\text { Relative } \\
\text { difference }\end{array}$ & $-30.5 \%$ & $-44.7 \%$ & $+2.1 \%$ \\
\hline$j(\mathrm{CFD})$ & 0.013 & 0.013 & - \\
\hline$j(\mathrm{M} \& \mathrm{~B})$ & 0.017 & 0.017 & \\
\hline $\begin{array}{c}\text { Relative } \\
\text { difference }\end{array}$ & $-21.2 \%$ & $-19.5 \%$ & $+10.2 \%$ \\
\hline$j / f^{1 / 3}(\mathrm{CFD})$ & 0.035 & 0.038 & \\
\hline
\end{tabular}

Table 3: $\quad$ Results for the compression-molding process design.

\begin{tabular}{|c|c|c|c|}
\hline & Rectangular edges & Rounded edges & Relative difference \\
\hline$f(\mathrm{CFD})$ & 0.097 & 0.035 & $-64.2 \%$ \\
\hline$f(\mathrm{M} \& \mathrm{~B})$ & 0.085 & 0.085 & - \\
\hline $\begin{array}{c}\text { Relative } \\
\text { difference }\end{array}$ & $+14.7 \%$ & $-58.9 \%$ & \\
\hline$j(\mathrm{CFD})$ & 0.014 & 0.009 & $-33.4 \%$ \\
\hline$j(\mathrm{M} \& \mathrm{~B})$ & 0.011 & 0.011 & - \\
\hline $\begin{array}{c}\text { Relative } \\
\text { difference }\end{array}$ & $+24.6 \%$ & $-17.0 \%$ & $-6.2 \%$ \\
\hline$j / f^{1 / 3}(\mathrm{CFD})$ & 0.031 & 0.029 & \\
\hline
\end{tabular}

for the design are different from CFD simulations results. It is due to the nonvalidity of the correlations for such geometrical parameters and Reynolds number. Having the simulated and more trustable values of $f$ and $j$, it is possible to compare the performances for both edge shapes. Rounding the edges off obviously reduces the pressure losses since it reduces the flow recirculations and turbulence. The heat transfer should be reduced too: it is true for the compression molded fins design. The injected fins design seems to be globally less affected by the edge shape in term of pure values of $f$ and $j$. For this flow, the value of Colburn convective heat transfer factor is more or less the same whatever the edge shape.

Using the classical performance factor $j / f^{1 / 3}$, the rounded edges seem better for the injected design flow while it seems better to have rectangular edges in the compression molded design.

\section{Conclusions}

A nanocomposite polymer heat exchanger using plate and fins has been designed.

Two processes are being investigated to manufacture the plates: injection and compression molding. 
On air side OSF fins have been used, validity of standard correlations for thermohydraulic design of these fins has been checked by CFD simulations and correction factors developed.

Prototypes under development will be tested to verify the design.

\section{Acknowledgements}

The research leading to these results has received funding from the European Community's Seventh Framework Program (FP7 2007-2013) under grant agreement n॰227407 - THERMONANO.

We thank all partners from the Program for fruitful discussions and for manufacturing the prototypes to be tested.

\section{References}

[1] Deronzier J.C. et al. Les échangeurs de chaleur en matière plastique, Ed Tech et Doc, 1989.

[2] Zaheed L., et al. Review of polymer compact heat exchangers, with special emphasis on a polymer film unit, Applied Thermal engineering, 24, pp. 2323-2358 2004.

[3] T'Joen, C. et al. A review on polymer heat exchangers for HVAC\&R applications, International Journal of Refrigeration, 32(5), pp. 763-779, 2009.

[4] AB Segerfröjd, http://www.segerfrojd.com

[5] Ametek http://www.ametekfpp.com

[6] Georg Fisher http://www.us.piping.georgefischer.com

[7] Greenbox http://www.greenbox.uk.com

[8] Milieupartners http://www.milieupartners.nl/index.htm

[9] SGL Carbon http://www.sglgroup.com

[10] Han, Z. and Fina A., Thermal conductivity of carbon nanotubes and their polymer nanocomposites: A review, Progress in Polymer Science, 36(7), pp. 914-944, 2011.

[11] Subramanian S., Ms C Thesis University of Nevada, 2005.

[12] Kim M.S. et al. Correlations and optimization of a heat exchanger with offset-strip fins, International Journal of Heat and Mass Transfer, 54(9-10), pp. 2073-2079, 2011.

[13] Dong J. et al. Air-side thermal hydraulic performance of offset strip fin aluminum heat exchangers, Applied Thermal Engineering, 27, pp306-313, 2007.

[14] Michel F., Optimisation des échangeurs compacts à ailettes: étude numérique et expérimentale, Ph.D. Thesis Univ. Joseph Fourier (Grenoble, France), (2003).

[15] Tochon P., Personal communication (2003).

[16] Manglik R.M. and Bergles A.E., Heat transfer and pressure drop correlations for the rectangular offset strip fin compact heat exchanger, Experimental Thermal and Fluid Science, 10(2), 1995. 